\title{
Commentary
}

\section{Standards for Half a Lifetime - A Personal Memoir}

\author{
Peter I. Adams \\ The Gables, 18 The Street, Uley, Glos. GL11 5TB, UK, e-mail: adams@rowberrow.fsnet.co.uk
}

\section{INTRODUCTION}

I was very honoured when the Editors asked me to write some account of my many years in the tobacco industry with particular reference to my activities in the Technical Committee ISO/ TC 126 "Tobacco and tobacco products" of the International Organization for Standardization (ISO).

After the Army, Oxford and physics applied in two other industries, I joined Imperial Tobacco in 1962 and was asked to measure the combustion temperatures of burning cigarettes, pipes and cigars. It is now curious to recall that at that time the use of dozens of 0,001 inch $\mathrm{Cu} / \mathrm{Ni} \mathrm{Ni} / \mathrm{Cr}$ thermocouples was possibly the only way to do it.

We were not much advanced from the period in the $50 \mathrm{~s}$ where statistics had to be computed using hand calculators to add values taken from tables of squares. The innovation was the use of a radiation pyrometer but what was the emissivity of a tobacco coal covered in ash? I am pleased that the definitive work of Dr Baker (1) did not show me to be very much in error. Moving from airflow rate studies in cigarette rods, I began to try to assess the puffing patterns of people smoking cigarettes principally but also cigars (2) and pipes.

The crude flow-rate puff shapes were the subject of a paper at the Tobacco Chemists' Research Conference (TCRC) in 1966 (3). I remember discussing the bell shape with the original director, Dr Pillsbury, of the US Federal Trade Commission (FTC) laboratory, who at that time was wondering whether to adopt the piston driven Phipps \& Bird smoking machine for the FTC measurements. Attempts to measure the smoking process followed with estimates of the values of puff volume, duration, interval and butt length. It was immediately apparent that each smoker smoked differently and each may smoke differently at different times and on different occasions. The principle of compensation was investigated and papers published. The subject is comprehensively covered in Dr Scherer's 1999 paper (4).

We developed an early reproducing smoker, at that time using punched paper tape and followed it using magnetic tape when the technology arrived. I think it is sometimes forgotten that when and if compensation occurs between different cigarettes, it also occurs during the puffing of a cigarette. Compensation may occur to obtain more smoke components but it also occurs to get less. Puff volumes are observed to decrease during the smoking of a particular cigarette so that I would guess that an intense test regime using a constant large puff volume is unlikely to correlate with any other characteristic to be studied.

\section{STANDARDISATION}

It is a small step from all this to standardisation. I began that work for Imperial Tobacco in 1973 in the British Standards Institution (BSI) Tobacco Technical Committee as a member becoming subsequently its chairman and leader of the UK delegation to TC 126 . I became chairman of TC 126 as a great surprise. I was minding the UK's business at the Paris meeting in 1985 when it was announced that $\mathrm{Dr}$ Artho was unable to continue because of his business commitments. The then TC 126 Secretary, Mr Ziethen, proposed me and I was elected for 1 year. I have now had the great pleasure of serving with two further secretaries, $\mathrm{Dr}$ Bohnsack and now Dr Heinrich. I seem to have been internationally acceptable so as to be re-elected on 6 subsequent occasions.

\section{Working Group 3}

In 1973, TC 126 Working Group (WG) 3 had just been established to standardise routine analytical smoking machines, work which produced ISO 3308. I attended my first meeting as an expert at the Hotel Schweizerhof in Berlin in 1973. My problem was that I had broken my Achilles tendon and appeared at the meeting in plaster and on crutches aided by a kind colleague. It is I think the only time so far that TC 126 has seen such a thing. Even at that time it was difficult to cross Budapester Strasse from the Hilton let alone having to cope with crutches! My ISO experience has not been without humorous incidents. At a subsequent meeting there making a quick exit after propos- 
ing a vote of thanks, I found myself in a cupboard full of cleaning materials and vacuum cleaners. I reappeared more quickly to WG 3's experts' surprise.

One of the principal problems of standardisation is illustrated by the long life of this group. Unless the work proceeds with great speed, various sets of apparatus and methods of analysis are developed and become established in different laboratories. Consensus on one method is difficult because no one wishes to give up his/her existing method and so lose continuity of the data.

At the time of the work on ISO 3308, the 1973 position was that a linear piston smoker giving a bell shaped puff, trapping smoke by a glass-fibre trap was in wide use. So also was a rotary machine using a square-wave puff and an electrostatic trap. Consensus was not possible until the rotary machine was redesigned to produce a bell shaped puff. Even so TC 126 decided that the standard ISO 8453 using an electrostatic trap was necessary. Generally two standards to measure nominally the same property is bad standardisation and ISO 8453 was eventually withdrawn.

Two of us worked as an ad-hoc group of WG 3 to draft Annexes B + C (still in the current version of ISO 3308). On returning from a meeting in Bremen, the plane was carrying a group of British sailors returning home for Christmas from a ship docking there. The duty free was opened and a blue and red parrot escaped from hand luggage and flew round the cabin. A Scots voice said "that's the only time that b . . . will fly at 30.000 feet"!

\section{Development subsequent to the WG 3 work}

The fundamental difference in design still results in a small difference in smoking data from the two designs (each permitted by ISO 3308) but has largely been reduced by further standardisation of the air flows in the machines. This was the result of a very large programme of work done by the Co-operation Centre for Scientific Research Relative to Tobacco (CORESTA) over a period of time and led to a complete 1991 revision of the smoking standard set ISO 3402, 3308, 4387, 10315 and 10362-1. The collaborative tests showed improved levels of repeatability and reproducibility (5). No financial accounts exist but I would guess that many million pounds were spent by the large number of people and laboratories involved.

Even after this level of activity the standards give no indication of the component of variability due to the product. This is because the cigarettes have to be sampled from special batches of product in order to make the best possible estimate of repeatability $(r)$ and reproducibility $(R)$. I do not think it will ever be possible to estimate this innate variability due to the cigarettes and the sampling procedure. Cigarettes also present the measurement problem that each may only be smoked once. How nice it would be to deal with a standard about, say, engineering nuts and bolts. A particular sample could be measured and re-measured by different people and then in different laboratories. It would then be absolutely clear what the $r$ and $R$ were. The manufacturer also has the problem that it is never known how the product will be smoked, a problem shared with motor car fuel manufacturers about the combustion of their product.

WG 3 also continued to draft ISO 4387, the method of using the smoking machine. It is worth saying that the text is still largely based on the method to test cigarettes that was used at that time in the voluntary agreement between the UK industry and the British government. It provided ranking data for the official yield league tables and the 'tar' bands into which cigarettes were classified.

ISO 8243 has just been revised by WG 8 . The need was to include tolerances for carbon monoxide. We have broken new ISO ground in the introduction of an ISO Technical Report 22305 (6) that will record the statistical methods and the data upon which the tolerances are based. For clarity the graphs are in colour: an ISO innovation. For years there has always been a question as to where the data for 'tar' and nicotine tolerances in the $1^{\text {st }}$ edition came from. This will not be the case this time.

\section{WG 7 - Fine-cut tobacco}

I was convener of WG 7 recently that was established to develop the set of standards (ISO 15592 parts 1-3) for the conditioning, manufacture and measurement of smoke yields of fine-cut tobacco articles (roll your own cigarettes). Much of the initial work had been done by CORESTA but the WG drafted the ISO standards and conducted a large collaborative study. There is a record of the work published in this journal (7). In this instance the colour photographs needed to demonstrate the laboratory apparatus did not meet with ISO approval.

The committee probably has an item of unfinished business revealed by this work. There is no ISO method for the measurement of tobacco rag filling power. The firmness of a smoking article is related to the filling power and it would possibly be helpful to the industry to have an appropriate standard. It will not be easy because the most interested parties probably have their own method in existence.

\section{Independence of the Committee}

There is a need to consider the relationship between CORESTA and TC 126. The committee and I were accused (8) of being under the control of CORESTA. This in fact is the only occasion in 20 years when I have been greatly hurt because of this unfounded allegation. Dr Baker published a reply to the article in this Journal (9).

I was involved in the CORESTA Technology Group from 1973 until 1984, sometime as its Chairman and as a member of the Scientific Commission. I have always been invited to the CORESTA annual meetings but as a matter of principle since becoming Chairman of ISO/TC 126 I have not attended such a meeting although my contemporary general knowledge of the industry would have been increased. A Chairman faces the dilemma that most of the delegates to ISO meetings work in CORESTA study groups and to ask them to duplicate attendance at other ISO working groups on the same subject is clearly a waste of their valuable time. Any suggestion in past years that work by CORESTA is flawed because it is done by the tobacco industry is unwarranted. The concept of a chairman with no knowledge of tobacco science and no connection with industry and possibly little knowledge of ISO procedures would throw an almost impossible task on the committee Secretary. The ISO Directives demand that a chairman acts internationally and neutrally ... this is what I have tried to do to the best of my ability. 
If it were possible, I believe that ISO itself should provide the necessary financial support for its chairman. It probably costs about $\$ 8000 /$ annum to travel to and stay in hotels to conduct meetings. There are, in addition the costs of communication, phone, fax and e-mail between the Chairman and the Secretariat particularly when they live in different countries. It is unlikely that many chairmen could support these costs on a charitable basis. The UK industry has supported me for 20 years and never has there been any attempt to influence me in the way I have conducted the committee business during that time.

\section{Initiation of new work and standard development}

ISO's strength and weakness is its procedure for standard development. As a first step the new work item proposal is required with acceptance rules. Few proposals have not been accepted at this stage. A justification is required as are offers by member bodies to participate in the work. This is not usually a problem as almost all the proposals reflect a perceived general need. Hence to the Working Drafts, Committee Drafts and Draft International Standards stages. It is when different opposing positions are taken that the reconciliation to a consensus position is required and can be a problem. The ISO definition is that there should be no sustained opposition. I have seen opposition disappearing during a meeting by the "art of the coffee break" - a break taken, possibly not at coffee time, when discussions occur off the public record of the meeting. A short or long-term ad hoc group is another weapon of a chairman. Overall although against the rules, a chairman taking part in the discussions and playing devil's advocate can be very helpful. It sometimes brings opposing parties together in the face of a third less desirable option.

TC 126 meetings have always been conducted using consecutive translation between the two ISO languages of French and English. Some consider this to be time wasting but I believe that, properly done, it is advantageous in that it gives delegates the opportunity of reflection upon hearing statements twice.

\section{Future work}

There is much work for the Committee to do apart from the routine revision of the large portfolio of existing standards. There is probably a need to provide ISO versions for the methods of analysis of some of the many of the so called "Hoffmann analytes". For example the programme of work already contains tobacco specific nitrosamines and benzo $[a]$ pyrene determination. Action will be required on the output from WG 9. That Group's primary proposal for a more intense smoking regime than that of ISO 4387 is somewhat akin to the Massachusetts one. After drafting and possibly development of a device to reduce the ventilation perhaps by covering half the periphery of the ventilation zone, such an ISO method will require a major international collaborative study to determine $r$ and $R$.

\section{CONCLUSION}

At a rough count, ISO has meant that I have travelled to 15 countries ranging globally from China to USA via Cuba and from Germany/Denmark to South Africa. What a privilege, pleasure and set of extraordinary experiences. I was offered the invitation by Cuba whilst in the bath in Beijing! We have happily passed through the visa problem of South Africans travelling to meetings, we have survived the problems of accepting an invitation to hold a meeting in a country temporarily suspended from membership under ISO rules.

This memoir has not been an example of an ISO scope that shall be "succinct so that ..." and I cannot end without a word of thanks to all the hundreds of colleagues I have met over the years, many of whom have become close friends. I shall miss them and the stimulation and interest that I have enjoyed by being allowed to think about the Committee's business long after I thought I had retired. Many thanks are due to the very helpful people in the German Institute of Standardization DIN (Deutsches Institut für Normung) who have understood my computer illiteracy and particularly to Mrs Baumann who began in the committee when I did and who has deciphered more of my ever worsening hand writing than almost any one else. In the words my Scots grandfather may have used, I would say to the committee "lang may y'r lumb reek". A literal translation being "long may your chimney smoke" very apt for a tobacco committee but my intention is to wish the committee future success.

\section{REFERENCES}

1. Baker, R.R.: Temperature variation within a cigarette combustion coal during the smoking cycle; High Temp. Sci. 7 (1975) 236-247.

2. Adams, P.I.: Cigar smoking: Measurement of the human smoking regime and its relationship to smoking machines; CORESTA Bulletin 1972, Special Abstract No. 78.

3. Adams, P.I.: Measurements on puffs taken by human smokers; Paper presented at $20^{\text {th }}$ Tobacco Chemists Research Conference, Winston Salem, NC, USA, Programme Booklet and Abstracts No. 31, 1966.

4. Scherer, G.: Smoking behaviour and compensation, a review of the literature; Psychopharmacology 145 (1999) 1-20.

5. ISO Bulletin 23 (1): Title? Jan. 1992, ISSN 0303-8057.

6. ISO/TR 22305: Cigarettes - Measurement of nicotinefree dry particulate matter, nicotine, water and carbon monoxide in cigarette smoke - Analysis of data from collaborative studies reporting relationships between repeatability, reproducibility and tolerances.

7. Adams, P.I.: Measurement of the "tar" and nicotine yield of fine-cut smoking articles - the ISO/TC 126 collaborative study 2001; Beitr. Tabkaforsch. Int. 21 (2004) 139-155.

8. Bialous S.A. and D. Yach: Whose standard is it, anyway. How the tobacco industry determined the ISO standards for tobacco and tobacco products; Tob. Control 10 (2001) 96-104.

9. Baker, R.R.: The development and significance of standards for smoking machine methodology; Beitr. Tabakforsch. Int. 20 (2002) 23-41. 